\title{
Study on Environment and Carbon Sequestration Effect of Wood Structure Building Based on Sustainable Development
}

\author{
Jie Fan', Lei Chen ${ }^{1}$, Dashan Zhang ${ }^{1}$, Haijie $\mathrm{Nie}^{2}$, An Mao ${ }^{3,}$, Laicheng Yang ${ }^{3,}$, Yifu Yuan ${ }^{3, *}$ \\ ${ }^{1}$ Planning and Design Institute of Forest Products Industry of National Forestry and Grassland Administration, Beijing, China \\ ${ }^{2}$ Qingfeng County Finance Bureau, Puyang, China \\ ${ }^{3}$ College of Forestry, Shandong Agricultural University, Taian, China
}

\section{Email address:}

117562841@qq.com (Jie Fan), 815464706@qq.com (Lei Chen), 10130034@qq.com (Dashan Zhang), 1461126360@qq.com (Haijie Nie), dannymaoan@126.com (An Mao), yanglcc@126.com (Laicheng Yan), yuanyf16@163.com (Yifu Yuan)

${ }^{*}$ Corresponding author

\section{To cite this article:}

Jie Fan, Lei Chen, Dashan Zhang, Haijie Nie, An Mao, Laicheng Yang, Yifu Yuan. Study on Environment and Carbon Sequestration Effect of Wood Structure Building Based on Sustainable Development. American Journal of Environmental Science and Engineering.

Vol. 4, No. 4, 2020, pp. 65-69. doi: 10.11648/j.ajese.20200404.13

Received: November 18, 2020; Accepted: November 30, 2020; Published: December 4, 2020

\begin{abstract}
Carbon Storage Estimation of wood products is one of the important directions of international climate change. As a building material of ecological sustainable development, wood structure building has many advantages, and its performance is better than other structures in many aspects. Forest products are sustainable. If forest products come from sustainably managed forests, and if they follow some principles of sustainable management, then wood, as a material and a product of wood products in daily life, is far more sustainable than other materials, from buildings to furniture. In this paper, the wood structure building is briefly introduced. On this basis, the role of wood structure product carbon flow in forest carbon storage and the impact on the environment are elaborated, which points out the direction for the development of related research in the future. The results are as follows: wood has little impact on climate in the whole life cycle and beyond, and its carbon emission in the life cycle is far lower than that of traditional building materials. The performance of wood structure building constructed with wood building materials is better than that of reinforced concrete structure in terms of energy saving, earthquake resistance, environmental protection and durability. The external ecological environment has a certain positive impact, promoting the sustainable development of society and the harmonious coexistence of man and nature.
\end{abstract}

Keywords: Carbon Sequestration, Wood Structure Building, Sustainable Development, Life Cycle Analysis

\section{Introduction}

The traditional wood and brick structure is the main structure in China. However, with the development of economy and society, the modern architecture in China is mainly reinforced concrete structure, and the development of wood structure in western countries is gradually mature [1]. As a building material of ecological sustainable development, wood structure building has many advantages, and its performance is better than other structures in many aspects. At present, modern wood structure has developed into a perfect and independent system [2].

About $25-30 \%$ of the global annual greenhouse gas emissions come from the construction industry, so the form of building plays an important role in climate change. One of the important ways to mitigate climate change is to find a way to fix carbon from the atmosphere [3-5]. As a natural and renewable resource, wood is also a kind of building material that can fix carbon dioxide. The emission of carbon dioxide can be reduced by about 1 ton per cubic meter of wood. The carbon emission of wood building materials in its life cycle is far lower than that of traditional building materials. The performance of wood structure buildings built with wood building materials is better than that of reinforced concrete structures in terms of energy saving, earthquake resistance, environmental protection and durability. Moreover, 
wood structure buildings can play an excellent role in carbon fixation, thus having a positive impact on the external ecological environment and promoting the sustainable development of society exhibition and the harmonious coexistence of man and nature [6]. In this paper, the carbon emission in the process of using wood structure building is taken as the research object, and the influence of wood structure on carbon emission is studied.

\section{Influence of Wood Structure Building on Environment}

The traditional construction industry relies heavily on concrete and steel, the two main materials. Of course, the environmental cost of doing so is obvious [7]. It is estimated that concrete accounts for $4-8 \%$ of global carbon emissions. The stone sand needed to produce concrete is the most used mineral material on the earth, accounting for $85 \%$ of the total mining volume in the world, and the supply bottleneck of concrete raw materials has been encountered in the world. It is the high pollution characteristics of concrete materials that many architects have begun to call for the return of wooden buildings. Extracting wood from sustainably managed forests is estimated to store about one ton of carbon dioxide per cubic meter of wood. One ton of carbon dioxide is equivalent to the carbon emissions from burning 350 liters of gasoline. Not only does wood need to absorb carbon itself, but it also consumes less energy than concrete and steel in the process of manufacturing [8-10]. In terms of energy consumption, the construction of steel structure houses consumes $17 \%$ more energy than wood structure houses, and the construction of concrete structure houses consumes $16 \%$ more energy than wood structure houses. The energy here is not only electric energy, but also fuel oil consumed in the transportation of building materials and natural gas consumed in the construction process.

\section{Life Cycle of Wood Structure Building}

Life cycle is generally understood as the process of a product from its birth to its death, which constitutes a complete product life cycle. Life cycle analysis (LCA) is a method used to quantify the environmental impact of various links in the process of raw material mining, transportation, production, use to waste treatment or recycling. LCA was first proposed by the society of environmental toxicology and Chemistry (SETAC) in 1990. The International Standard Organization (ISO) defined LCA as a method to analyze and evaluate the impact of all inputs and outputs of a product on the surrounding environment during its whole life cycle [11].

The life cycle of architecture includes the following stages (Table 1): (1) exploitation of resources: exploitation and transportation of raw materials; (2) Production of building materials: production, processing and transportation of building materials; (3) construction of buildings: installation and fixation of building materials, construction of buildings, etc.; (4) use and maintenance of buildings: energy consumption of water, heating, ventilation, air conditioning, lighting, etc. is the longest stage in the whole life cycle of buildings; (5) demolition and recycling of buildings: including demolition of building structures and material treatment waste recycling and reuse. The life cycle of wood structure building includes the same five stages. In North America, LCA is used to track, quantitatively analyze and qualitatively evaluate the process of raw material mining, equipment production, component processing and manufacturing, construction and installation, operation and maintenance, demolition and recycling of modern wood structure buildings in North America. The database of environmental properties of wood structural materials is established and expanded [12]. With the continuous development and improvement, LCA has become one of the main methods to evaluate the environmental performance of timber structures.

\section{Carbon Storage of Wood Structure Building}

Since a large amount of carbon can be stored in the wood components of buildings, it is also important to ensure that carbon is stored for as long as possible. If you want to prolong the service life, you need good design, good moisture protection during construction and good maintenance. When wooden components are no longer used in buildings, they are likely to be recycled for other products, so carbon in the atmosphere is still locked in. After continuous recycling, wood can be used for carbon neutral bioenergy production. Wooden materials can be used in most structures of any building to capture carbon from the atmosphere. This makes it possible for designers and builders to achieve ambitious targets to reduce carbon dioxide emissions [13]. The greatest potential for carbon storage can be achieved in exterior walls, intermediate floors and roof structures. For example, passive buildings designed for cold weather have two alternative building materials: wood frame with wood fiber insulation and concrete frame with EPS insulation.

Wood structure building made of wood is a kind of carbon negative product, which can play a role in carbon fixation [14 15]. In the UK, $15-28 \%$ of new buildings are built in wood every year. These wooden structures store about one million tons of carbon dioxide a year. If the use of wood buildings can be increased, this carbon reduction effect can produce greater advantages.

The earth uses forests to balance the carbon cycle in the atmosphere, which is why forests are called the lungs of the earth. When the trees reach the mature stage, their absorption rate of carbon dioxide will be greatly reduced. After the trees die and fall, they will be decomposed into carbon dioxide and emitted into the atmosphere. Therefore, the best solution is to manage and utilize forest resources reasonably. Many third-party forest certification agencies require 2-3 trees to be 
replanted for each tree cut. The important role that sustainable forest industries can play in mitigating climate change. The wrong impression that using wood is not environmentally friendly comes from the unilateral perception of cutting down trees. This concept should be changed. What we want to emphasize now is sustainable forest management. When we cut down trees, we replant them in time. Carbon can therefore be permanently fixed in the wood that has been cut down [7, 8].

Forest products are sustainable. If forest products come from sustainably managed forests, and if they follow some principles of sustainable management, then wood, as a material and a product of wood products in daily life, is far more sustainable than other materials, from buildings to furniture.

The construction industry accounts for $30 \%$ of the global annual greenhouse gas emissions, so reducing the carbon footprint of the construction industry plays an important role in mitigating climate change. Building houses with wood is one of the most effective solutions, because wood is the only natural building material that can fix carbon. Wood products have surprisingly small carbon emissions over their life cycle, and carbon can be permanently fixed in wooden buildings. One of the most important ways to mitigate climate change is to find new ways to absorb and store carbon from the atmosphere. Wood products can absorb and fix about 1 ton of carbon dioxide per cubic meter of wood, and the construction industry can use carbon fixing wood building materials to help reduce the carbon footprint. Wood materials can be used in most of the structure of any building, so as to achieve the purpose of carbon sequestration. This allows designers and builders to achieve the goal of reducing carbon emissions. The maximum potential of carbon sequestration can be achieved in exterior wall, floor and roof structures. For example, passive rooms designed for cold climates have two alternative exterior wall systems: wood frame walls filled with insulation and concrete walls insulated with EPS [10].

Wood has little impact on the climate throughout its life cycle and beyond. Since a large amount of carbon can be fixed in the wood components of buildings, it is also important to ensure that carbon is stored for as long as possible. In order to extend the service life, it is necessary to have good design, good moisture-proof during construction and good maintenance. When wooden components are no longer used in buildings, they can also be recycled - so carbon in the atmosphere is still locked in. Even after the wooden frame building is dismantled, its wooden components can still be used as biofuel for bioenergy.

Table 1. Life cycle of architecture includes the following stages.

\begin{tabular}{lll}
\hline No. & Life cycle stage of architecture & The content of the stage \\
\hline 1 & Exploitation of resources & Exploitation and transportation of raw materials \\
2 & Production of building materials & Production, processing and transportation of building materials \\
3 & Construction of buildings & Installation and fixation of building materials, construction of buildings, etc. \\
4 & Use and maintenance of buildings & $\begin{array}{l}\text { Energy consumption of water, heating, ventilation, air-conditioning, lighting, etc. the longest stage in the } \\
\text { whole life cycle of buildings }\end{array}$ \\
5 & Demolition and recycling of buildings & Demolition of building structures and material treatment waste recycling and reuse \\
\hline
\end{tabular}

\section{Carbon Emission of Wood Structure Building}

\subsection{Carbon Emission of Building}

An important environmental assessment index in LCA is carbon emission. Building carbon emission refers to the sum of greenhouse gas emissions produced by buildings in the production and transportation, construction and demolition, and operation stages related to building materials. It includes: 1) carbon emissions in the production and transportation of building materials, such as steel bars, concrete, glass and other major building materials, as well as the transportation from the production site to the construction site; 2) the carbon emissions generated during the construction process; 3) the energy sources such as HVAC, domestic hot water, lighting, elevator and gas in the process of building operation In the process of building demolition and recycling, the carbon emissions from various energy sources consumed by manual demolition and mechanical demolition of small machinery and equipment, as well as the carbon emissions from waste recycling, transportation, landfill and incineration after demolition. Carbon dioxide is the main greenhouse gas emissions, and the life cycle of buildings is generally as long as several decades. In the long life cycle, how to reduce building carbon emissions through energy conservation and emission reduction measures is a hot environmental protection issue.

\subsection{Carbon Emission in the Process of Using Wood Structure Building}

The use and maintenance stage of public buildings refers to the period from the completion of buildings to the demolition of buildings. China Academy of Building Sciences Co., Ltd. has studied and compared the carbon emissions of wood structure buildings in different stages of their life cycle. The results show that if the carbon emissions of the whole life cycle of buildings are calculated as $100 \%$, the carbon emissions of buildings in the process of use and maintenance account for the carbon emissions of the whole life cycle $8 \%$ 95.4\%. The carbon emissions in other stages are: $0.8 \%-12.1 \%$ for building materials mining and production, $0.1 \%-0.3 \%$ for building materials transportation, and $1.9 \%-2.4 \%$ for building construction and demolition. Therefore, the construction use and maintenance stage is the longest period in the construction life cycle, and it is also the most important link to affect the carbon emissions. The carbon emissions in the construction use and maintenance stage are mainly the use of some building 
equipment in the household living system, and some greenhouse gases are emitted into the environment by the use of some building equipment in the living system. Reducing the carbon emission in this link is of great significance to reducing the overall carbon emission

\subsection{Calculation of Carbon Emission During Building Service}

According to the national standard "calculation standard of building carbon emission", the carbon emission of building operation stage involves the calculation of carbon emission generated by energy consumption of HVAC, domestic hot water, lighting and other systems, the capacity reduction of renewable energy system and the carbon reduction of building carbon sink. At the boundary of building carbon emission, the different energy consumption is converted into the carbon emission of buildings, and the total carbon emission of buildings is obtained by summarizing. The carbon emission of buildings which are greatly affected by the use of power transformation and distribution, household appliances, office appliances, cooking, etc. is uncertain. This part of carbon emissions does not account for a high proportion of the total carbon emissions, and does not affect the judgment of the carbon emission intensity of the building scheme in the design stage. The international common practice does not include the carbon emission of household appliances, office appliances, cooking, etc. The national standard "general principles for design of civil buildings" GB 50325 divides the design service life of buildings into four categories, in which the design life of ordinary buildings is 50 years. Therefore, the design life of buildings used in carbon emission calculation should be consistent with the design documents. When the design documents cannot be provided, the design life shall be calculated as 50 years.

The building energy consumption system consumes terminal energy in the form of electric energy, fuel oil, coal and gas in the operation stage. The total building energy consumption is summarized according to different types of energy, and then the carbon emission of building energy system is calculated according to the carbon emission factors of different energy sources. The energy consumption of HVAC system consists of cold and heat source energy consumption, transmission and distribution system and terminal air treatment equipment energy consumption. The transmission and distribution system includes chilled water system, cooling water system, hot water system and air system. The annual heat consumption of domestic hot water in buildings is calculated according to the actual operation of buildings. The demand is related to the number of indoor personnel, usage habits and activity types. The value of lighting power density used in building carbon emission calculation should be consistent with the design documents, and the influence of natural lighting, control mode and use habits should be included. Energy consumption of elevator system is related to elevator speed, rated load, specific energy consumption and other parameters. Renewable energy system should include solar domestic hot water system, photovoltaic system, ground source heat pump system and wind power generation system. The energy consumption of ground source heat pump system should be mainly reflected in the efficiency of the system. Therefore, the energy consumption of renewable energy system is no longer calculated separately, but the energy conservation of HVAC system is calculated. For solar thermal or photovoltaic power generation, wind power generation and other systems, the energy consumption of different systems is calculated according to resource conditions, system type, system form, and system efficiency Energy consumption.

\section{Summary}

In this paper, the carbon emission in the process of using wood structure building is taken as the research object, and the influence of wood structure on carbon emission is studied. The results are as follows: wood has little impact on climate in the whole life cycle and beyond, and its carbon emission in the life cycle is far lower than that of traditional building materials. The performance of wood structure building constructed with wood building materials is better than that of reinforced concrete structure in terms of energy saving, earthquake resistance, environmental protection and durability, and the wood structure building can play an excellent role in carbon fixation. The external ecological environment has a certain positive impact, promoting the sustainable development of society and the harmonious coexistence of man and nature.

\section{Author Contributions}

The Manuscript was written through contributions of all authors. All authors have given approval to the final version of the manuscript.

\section{Conflicts of Interest}

The authors declare that they have no competing interests.

\section{References}

[1] Garcia J, Lippke B, Briggs D (2005) The environmental performance of renewable building materials in the context of residential construction. Wood and Fiber Science, 37: 3-17.

[2] Bowyer J D, Briggs B, Lippke J (2004) Life cycle environmental performance of renewable building materials in the context of residential construction. Consortium for Research on Renewable Industrial Materials. University of Washington, Seattle, WA.

[3] Borjesson P, Gustavsson L (2000) Greenhouse gas balances in building construction: wood versus concrete from life-cycle and forest land-use perspectives. Energy Policy, 28: 575-588.

[4] Jungmeier G, Werner F, Jarnehammer A (2020) Allocation in LCA of wood-based products; experiences of Cost Action E9; part I. methodology. The International Journal of Life Cycle Assessment, 7: 290-294. 
[5] Li H. B, Lin Z. F (2019) Study on forestry industry ecology based on circular economy. Jiangxi Agriculture, 12: 88-89.

[6] Cui W. Z (2019) Study on the development of forestry industry from the perspective of circular economy. Science and Technology Innovation Herald, 16 (19): 255-257.

[7] Li Z. Q, Qi J. G, Wu G. S (2008) New Basic Principles of Modern Circular Economy: From 3R to 5R. The Journal of Quantitative \& Technical Economics, 25 (1): 53-59.

[8] Zhang Z. Z (2019) Theoretical Logic of the "Material Circulation and Reutilization" Thought: Based on the dimension of Marxist Green Development. Journal of Central South University of Forestry \& Technology, 13 (1): 12-17.

[9] Werner F, Richter K (2007) Wooden building products in comparative LCA. The International Journal of Life Cycle Assessment, 12 (7): 470-479.

[10] Zeng J. Yu, H. Y. Zhang, D. D (2018). Comparison of carbon emission between wood structural materials and other building structural materials. Wood Industry, 32 (1): 28-32.
[11] P. Wei, X. Rao, J. Yang, Y. Guo, H. Chen, Y. Zhang, S. Chen, $\mathrm{X}$. Deng, and $\mathrm{X}$. Wang, Hot pressing of wood-based composites: a review. Forest Products Journal, 66 (7/8): 419-427, 2016.

[12] Xiong M. Z, Bao F. C (2006) Study on the development superiority of modern wood industry in recycling economy. Wood Industry, 20 (1): 5-7.

[13] China Forest Products Industry Association, State Forestry Bureau Forest Industry Planning and Design Institute. China Wood Based Panel Industry Report 2019. 2019.

[14] Ji M, Geng L. M (2019) Study on the development of forestry biomass energy based on forestry circular economy. China Forestry Economy, 5: 12-14.

[15] National Forestry and Grassland Administration. Code for Recycling Utilization of Waste Wood (LY/T1822-2019). Beijing: China Standards Press, 2019. 